\title{
Conformational flexibility and ligand binding properties of ovine $\beta$-lactoglobulin
}

\author{
Joanna I. Loch ${ }^{1 \otimes}$, Piotr Bonarek² and Krzysztof Lewiński \\ 'Department of Crystal Chemistry and Crystal Physics, Faculty of Chemistry, Jagiellonian University, Kraków, Poland; 2Department of Physical \\ Biochemistry, Faculty of Biochemistry, Biophysics and Biotechnology, Jagiellonian University, Kraków, Poland
}

Ovine $\beta$-lactoglobulin was characterized by spectroscopic (CD), calorimetric (ITC) and X-ray structural studies. The structure of ovine $\beta$-lactoglobulin complex with decanol showed that tight packing of molecules in the crystalline phase enforces a distortion of protein flexible loops resulting in the formation of an asymmetric dimer. The loops surrounding $\beta$-barrel in ovine lactoglobulin possessed the same conformational flexibility as observed previously in other lactoglobulins and the change of their conformation regulates the access to the binding pocket. The structure of asymmetric dimer revealed a new region in $\beta$-barrel where ligand polar group can be located. These findings indicated protein adaptability to ligand dimensions and inter- and intramolecular interactions in the crystalline phase. Calorimetric and crystallographic studies provided the experimental evidence that ovine lactoglobulin is able to bind aliphatic ligands. Thermodynamic parameters of sodium dodecyl sulfate binding determined by ITC at $\mathrm{pH} 7.5$ had $\mathrm{K}_{\mathrm{a}}, \Delta \mathrm{H}, \mathrm{T} \Delta \mathrm{S}$ and $\Delta \mathrm{G}$ values similar to those observed for bovine and caprine protein indicating the same mechanism of ligand binding.

Key words: $\beta$-lactoglobulin; decanol; asymmetric dimer; ligand, conformation

Received: 18 October, 2019; revised: 28 November, 2019; accepted: 04 December, 2019; available on-line: 27 December, 2019

$\square_{\text {e-mail: loch@chemia.uj.edu.pl }}$

*Acknowlkedgements of Financial Support:

The costs of the article published as a part of the 44th FEBS Congress Kraków 2019 - From molecules to living systems block are financed by the Ministry of Science and Higher Education of the Republic of Poland (Contract 805/P-DUN/2019).

This study was partially supported by the Polish National Science Centre, grant 2012/05/B/ST5/00278.

PDB accession numbers: $6 \mathrm{~T} 42$ and $6 \mathrm{~T} 44$

Abbreviations: BLG, cow (bovine) $\beta$-lactoglobulin; DEC, decanol, 1-decanol, decan-1-ol, n-decyl alcohol, capric alcohol; GLG, goat (caprine) $\beta$-lactoglobulin; LG, $\beta$-lactoglobulin; SLG, sheep (ovine) $\beta$-lactoglobulin

\section{INTRODUCTION}

Milk belongs to a group of basic nutritional products. Besides the most popular cow milk, nowadays, milk from other species as buffalo, goat, sheep, camel, horse, donkey and yak is available and consumed in some regions of the world (Claeys et al., 2014). Milk is an important source of proteins in the human diet. $\beta$-Lactoglobulin (LG) together with $\alpha$-lactalbumin and casein are the major milk protein allergens (Martorell-Aragonés et al., 2015; Villa et al., 2018). Although $\beta$-lactoglobulin is present in the milk of many mammals (Sawyer, 2013), it is not present in human milk. Among lactoglobulins from different species, the most thoroughly biochemically, biophysically and structurally studied is the bovine protein (BLG). Much less is known about ovine $\beta$-lactoglobulin (SLG) and its homolog from goat milk (GLG). Sheep protein, similarly to bovine one, has 162 residues and is dimeric at a neutral $\mathrm{pH}$ (Loch et al., 2014). The sequence of SLG isoform A used in all our experiments differs from BLG isoform B and goat protein (GLG) only at six positions located far from the binding pocket (Fig. 1) (Loch et al., 2014). Lactoglobulins belong
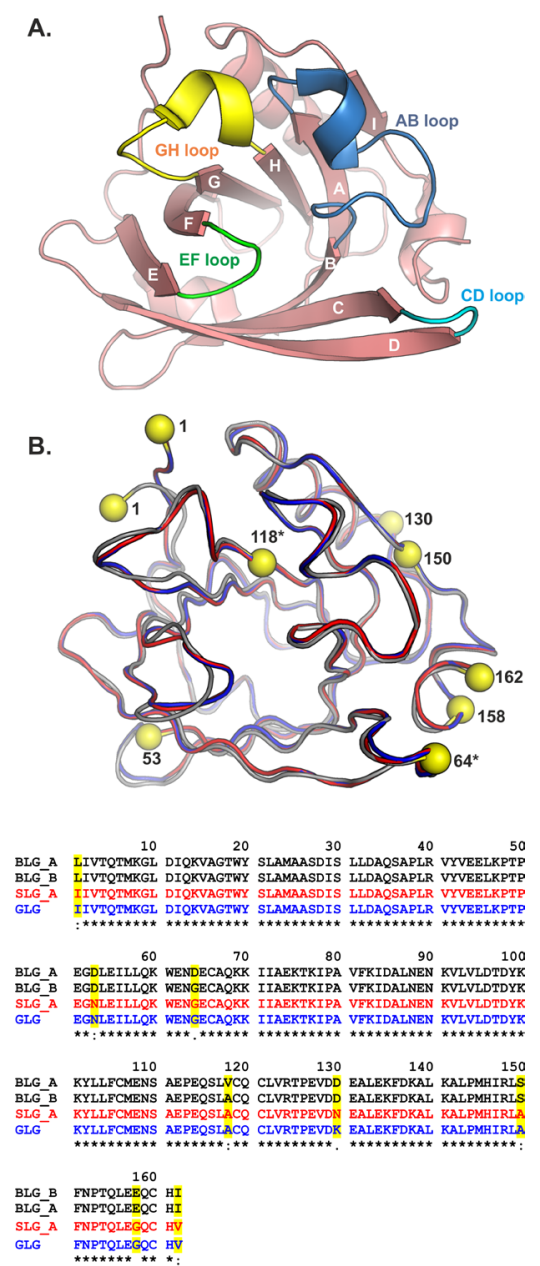

Figure 1. (A) The overall structure of ovine $\beta$-lactoglobulin (PDB ID: 4NLI). (B) Superposition of the structures: BLG_B (black, PDB ID: 3BLG), SLG A (red, PDB ID: 4NLI) and GLG (blue, PDB ID: 4OMX) with mutation sites marked by yellow spheres. Mutation sites present only in bovine lactoglobulin are marked with an asterisk.

Alignment of lactoglobulin sequences: bovine lactoglobulin isoform $A\left(B L G \_A\right)$ and isoform $B$ (BLG_B), ovine lactoglobulin isoform A (SLG_A) and caprine lactoglobulin (GLG). 
to the family of lipocalins, relatively small proteins that, despite diverse physiological functions, share the same 3 -dimensional structure. The core of the molecule is an 8 - or 9 -stranded $\beta$-barrel with flexible loops surrounding the entrance to the binding pocket located in the $\beta$-barrel interior (Fig. 1). This architecture makes lipocalins prone to modifications that change the affinity to selected molecular targets (Skerra, 2008; Loch et al., 2018).

The biological function of $\beta$-lactoglobulin has not been clarified up to date and almost all the available data describe the potential role of the protein from bovine milk. It was postulated that BLG has antioxidant activity and like other whey proteins is a potential glutathione transporter. Bovine $\beta$-lactoglobulin demonstrated resistance to gastric digestions and was proposed as a carrier for gastric-labile hydrophobic drugs (Tsutsumi \& Tsutsumi, 2014). It was also discovered that BLG has catalytic activity and can promote cyclodimerization of all-trans-retinal to cycloretinal (Gowda et al., 2017). Recently, the nutritional scientists focused their studies on bioactive peptides which are released when lactoglobulin is digested in the gastrointestinal tract or is affected by processing with the use of high temperature (Leeb et al., 2011) or high pressure (Zeece et al., 2008; Kurpiewska et al., 2018). These peptides, containing from 3 to $20 \mathrm{ami}-$ no acids per molecule, when released in the body may act as regulatory compounds with hormone-like function (Hernández-Ledesma et al., 2008; Power et al., 2014) or as dipeptidyl peptidase-4 inhibitors (Silveira et al., 2013; Tulipano et al., 2015).

Besides many possible functions, the transport of hydrophobic ligands seems to be the most important lactoglobulin role. Bovine $\beta$-lactoglobulin is well known for its ability to bind a wide range of compounds. Ligand binding to BLG is related to $\mathrm{pH}$-dependent conformational change called Tanford transition (Sakurai \& Goto, 2006). The number of recognized $\beta$-lactoglobulin ligands is estimated at more than 200 (Sawyer, 2013). Among them, fatty acids (Pérez \& Calvo, 1995) and retinol (Ciuciu et al., 2016) play a special role and are proposed to be the endogenous ligands for BLG. Extensive studies with the use of various techniques revealed that bovine $\beta$-lactoglobulin can bind predominately saturated and unsaturated fatty acids of the length from $\mathrm{C}_{8}$ to $\mathrm{C}_{22}$ (Le Maux et al., 2014).

Numerous biophysical and biochemical studies performed on bovine lactoglobulin did not allow to define its biological function, even less is known about the function of proteins from the other species, including goat and sheep. In this study, we investigated the ligand binding properties of sheep lactoglobulin. A model ligand, water-soluble aliphatic compound, sodium dodecyl sulfate (SDS) was selected to compare the association constants determined for SLG to the values determined earlier for the bovine (Loch et al., 2013b; Bonarek \& Polit, 2018) and caprine protein (Loch et al., 2015b). Presented biophysical and structural studies give insight into SLG conformational dynamics and ligand binding properties and bring closer the identification of its possible biological function.

\section{MATERIALS AND METHODS}

Protein isolation and purification. Sheep $\beta$-lactoglobulin (isoform A) was isolated from fresh homozygotous ovine milk according to the procedure described previously (Loch et al., 2014). The SDS-PAGE, as well as anion exchange chromatography (MonoQ

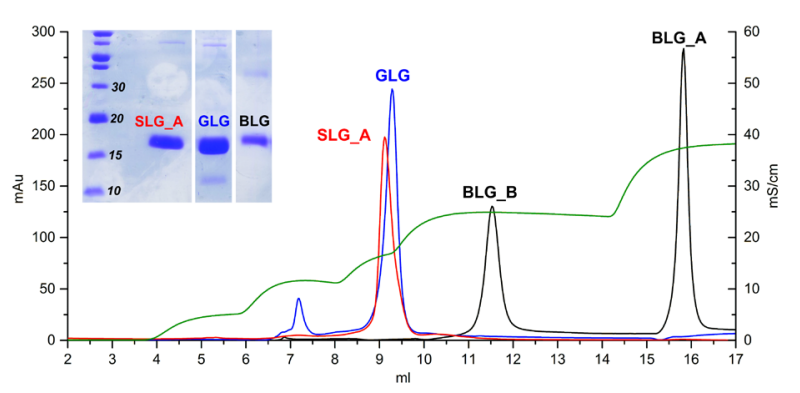

Figure 2. Chromatographic analysis (MonoQ $5 / 50$ column) of lactoglobulin isolated from ovine milk (SLG_A).

The chromatogram was superposed on similar separations performed for lactoglobulin isolated from caprine milk (GLG) and the mixture of two isoforms of bovine lactoglobulin (BLG_A and BLG_B) purchased from Sigma-Aldrich. Insert: SDS-PAGE analysis of SLG_A, GLG and BLG (a mixture of BLG_A and BLG_B) before loading onto MonoQ 5/50 column.

5/50 column GE Healthcare), were performed to check the homogeneity of the purified SLG (Fig. 2). The protein solution was prepared in water (water was also used instead of chromatographic buffer A) and SLG was eluted from the resin using a gradient of buffer $\mathrm{B}(0.7 \mathrm{M}$ $\mathrm{CH}_{3} \mathrm{COONa}$, $\mathrm{pH}$ 6.3). The resulting chromatogram, superimposed on chromatograms for similar separations carried out under identical conditions for goat lactoglobulin (Loch et al., 2015b) and a mixture of bovine lactoglobulin isoforms purchased from Sigma-Aldrich, is presented in Fig. 2.

Circular dichroism. Near-UV and far-UV CD spectra were recorded at $25^{\circ} \mathrm{C}$ on a JASCO J-710 spectropolarimeter using $50 \mathrm{mM}$ phosphate buffer $\mathrm{pH}$ 7.5. The protein concentrations of $70 \mu \mathrm{M}$ and $5 \mathrm{~mm}$ or $200 \mu \mathrm{m}$ path length were used for near-UV and far-UV measurements, respectively. Three scanning acquisitions were accumulated and averaged to yield the final spectrum. The CD spectra were corrected for the buffer baseline. The ellipticity was converted to a difference in extinction coefficients $(\Delta \varepsilon)$. The spectra were normalized to the path length and the peptide bonds concentration for far-UV and to the protein concentration for near-UV.

Isothermal titration calorimetry. ITC experiments of SDS binding were carried out at $\mathrm{pH} 7.5,25^{\circ} \mathrm{C}$ using a VP-ITC instrument (MicroCal, Northampton, MA, USA) according to the method described in detail in our previous paper (Loch et al., 2013b).

Crystallization. Crystals of the ovine $\beta$-lactoglobulin complex with decanol (SLG-DEC) were obtained using vapor diffusion method in a hanging drop setup, in drops formed by mixing $2 \mu \mathrm{l}$ SLG $(15 \mathrm{mg} / \mathrm{ml}), 0.5 \mu \mathrm{l}$ of decanol and $2 \mu \mathrm{l}$ of a well solution containing $1.30 \mathrm{M}$ sodium citrate in $0.2 \mathrm{M}$ Tris $\mathrm{pH}$ 8.5. Crystals of the bovine $\beta$-lactoglobulin complex with decanol (BLG-DEC) were obtained in drops containing $2 \mu \mathrm{l}$ of BLG $(20 \mathrm{mg}$ / $\mathrm{ml}), 0.5 \mu \mathrm{l}$ of decanol and $6 \mu \mathrm{l}$ of a well solution containing $1.34 \mathrm{M}$ sodium citrate in $0.1 \mathrm{M}$ Tris- $\mathrm{HCl} \mathrm{pH}$ 7.5. Drops were equilibrated against $500 \mu \mathrm{l}$ of the well solution. Bovine $\beta$-lactoglobulin isoform B $(\geq 90 \%)$ used for crystallization was purchased from Sigma-Aldrich.

Data collection, structure refinement and analysis. The diffraction data were collected using SuperNova diffractometer (Rigaku Oxford Diffraction) equipped with microfocus $\mathrm{CuK} \alpha(1.54 \AA, 0.8 \mathrm{~mA}$ and $50 \mathrm{kV})$ and $135 \mathrm{~mm}$ Atlas CCD detector. Crystals were immersed in a cryoprotectant $(20 \%, \mathrm{v} / \mathrm{v}$ glycerol in the well solution) and immediately transferred to nitrogen cryostream $(120 \mathrm{~K})$. Data were processed using Crysalis Pro (Rigaku 
Table 1. Statistics of the data collection and structure refinement.

\begin{tabular}{|c|c|c|}
\hline & SLG-DEC & BLG-DEC \\
\hline PDB ID & $6 \mathrm{~T} 44$ & $6 \mathrm{~T} 42$ \\
\hline \multicolumn{3}{|l|}{ Data processing } \\
\hline space group & $\mathrm{P}_{2}$ & $\mathrm{P}_{2} 21$ \\
\hline unit cell $[\AA ̊]$ & $\begin{array}{l}a=b=108.34 \\
c=55.86\end{array}$ & $\begin{array}{l}a=b=53.15 \\
c=111.41\end{array}$ \\
\hline resolution $[\AA ̊]$ & $\begin{array}{l}14.58-2.00 \\
(2.05-2.00)\end{array}$ & $\begin{array}{l}13.29-1.95 \\
(2.00-1.95)\end{array}$ \\
\hline total no. of unique reflections & $25315(1832)$ & $13734(944)$ \\
\hline$R_{\text {merge }}$ & $0.058(0.436)$ & $0.032(0.330)$ \\
\hline mean $1 / \sigma \mathrm{l}$ & $12.8(1.3)$ & $10.7(1.8)$ \\
\hline completeness [\%] & $99.6(99.7)$ & $99.2(99.2)$ \\
\hline$C C(1 / 2)$ & $0.997(0.728)$ & $0.999(0.871)$ \\
\hline multiplicity & $2.7(2.1)$ & $2.5(1.8)$ \\
\hline \multicolumn{3}{|l|}{ Refinement } \\
\hline no. of reflections (test) & $24126\left(\begin{array}{ll}1 & 170\end{array}\right)$ & $13638(1357)$ \\
\hline $\mathrm{R}[\%]$ & 19.6 & 17.4 \\
\hline $\mathrm{R}_{\text {free }}[\%]$ & 24.8 & 22.9 \\
\hline rms bonds $[\AA \AA]$ & 0.011 & 0.010 \\
\hline rms angles $\left[^{\circ}\right]$ & 1.686 & 1.582 \\
\hline \multicolumn{3}{|l|}{ Ramachandran statistics } \\
\hline favored [\%] & 98 & 97 \\
\hline allowed [\%] & 2 & 3 \\
\hline disallowed [\%] & 0 & 0 \\
\hline
\end{tabular}

Oxford Diffraction) and Aimless (Evans \& Murshudov, 2013) from the CCP4 package (Winn et al., 2011).

The structure of BLG-DEC was solved by molecular replacement in Phaser (McCoy et al., 2007) using bovine lactoglobulin structure $1 \mathrm{BSY}$ as a starting model. The structure of the SLG-DEC complex was solved using ovine lactoglobulin structure 4NLI as a model. Structures were refined in Refmac (Murshudov et al., 2011), Fourier maps were investigated in Coot (Emsley et al., 2010). Statistics of data collection and structure refinement are summarized in Table 1. The structures were deposited in Protein Data Bank as entries 6T42 (BLG-DEC) and 6T44 (SLG-DEC).

\section{RESULTS}

\section{CD spectra}

To compare SLG secondary and tertiary structure in solution at $\mathrm{pH}$ close to neutral $(\mathrm{pH} 7.5)$, to the structure of GLG and BLG, the circular dichroism spectra were recorded. The CD spectra of sheep $\beta$-lactoglobulin (Fig. 3) were compatible with the results obtained for goat and bovine protein (El-Zahar et al., 2004). The far-UV spectra indicated high secondary structure similarity of ovine lactoglobulin and its bovine and caprine homolog. However, the near-UV spectra showed some differences. In comparison to BLG (or GLG), the signal for ovine protein was more intense in the range of 260-290 nm, maintaining the characteristic minima at $268 \mathrm{~nm}$ originating from phenylalanine residues and at

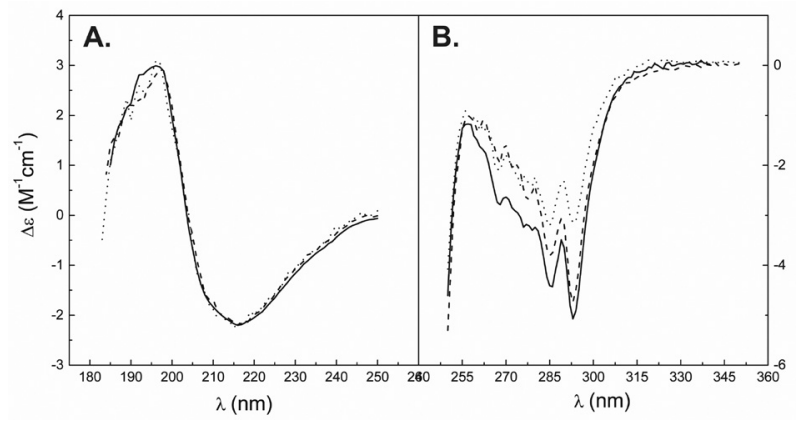

Figure 3. Far-UV (A) and near-UV (B) CD spectra of SLG (solid line), BLG_B (dashed line) and GLG (dotted line).

SLG spectrum was acquired using $70 \mu \mathrm{M}$ protein in $0.05 \mathrm{M}$ phosphate buffer, $\mathrm{pH} 7.5,25^{\circ} \mathrm{C}$. The $\Delta \varepsilon$ value was normalized to the peptide bonds or protein concentration. Spectra of BLG_B and GLG are from (Loch et al., 2015).

285 and $293 \mathrm{~nm}$ related to Trp19 hidden in the $\beta$-barrel bottom. Such results suggest that SLG has the most rigid structure among all the studied lactoglobulins (Loch et al., 2015b).

\section{Thermodynamics of ligand binding (ITC)}

The isotherms of SDS binding to ovine $\beta$-lactoglobulin recorded in three different buffers used (phosphate, Tris, Tricine) are presented in Fig. 4. In all cases, a model of one binding site was sufficient to describe the interactions. The calculated stoichiometry was always below 1.0 and varied in the range from 0.63 to 0.79 . The determined thermodynamic parameters (Table 2) indicate that the reaction is driven by favorable changes both in enthalpy and entropy, however, with entropy contribution to Gibbs energy almost twice higher. From the linear dependence of the observed enthalpies versus buffer ionization enthalpies, it was calculated that $0.51 \pm 0.04$ mole of protons is released during the formation of one mole of the complex (inset in Fig. 4).

\section{Crystal structures of SLG and BLG complexes with decanol}

The ovine protein used for crystallization had high purity as checked by SDS-PAGE (Fig. 2). Our efforts to obtain crystal of SLG complex with SDS (SLG-SDS)

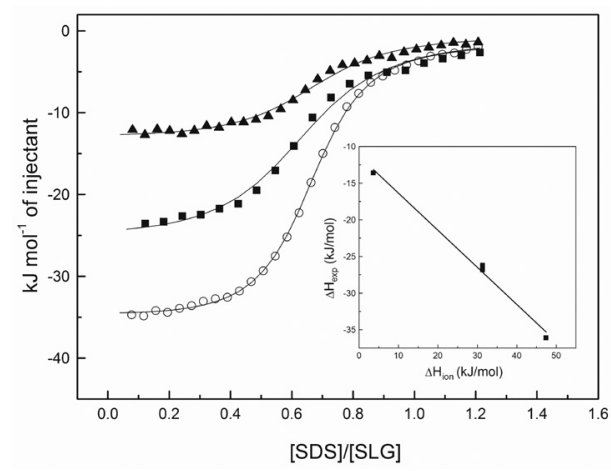

Figure 4. Calorimetric isotherms of SDS binding to SLG.

The experiments were performed in three buffers which differed in their ionization enthalpy: phosphate (black triangles), Tricine (black squares) and Tris (white circles) at the concentration of 0.05 $\mathrm{M}$ and $\mathrm{pH}$ 7.5. The solid line represents the best fit of the experimental data to the one-site binding model. The insert: dependence of the experimental binding enthalpy $\left(\Delta \mathrm{H}_{\text {exp }}\right)$ on the ionization enthalpy of the buffer $\left(\Delta \mathrm{H}_{\text {ion }}\right)$. 
Table 2. Thermodynamic parameters determined by ITC at $298 \mathrm{~K}$ for binding SDS to SLG in $50 \mathrm{mM}$ phosphate buffer pH 7.5. $\Delta \mathrm{G}$ was calculated according to the equation: $\Delta \mathrm{G}=-\mathrm{RT} \ln \mathrm{K}_{\mathrm{a}}$

\begin{tabular}{|c|c|c|c|c|}
\hline & SLG & GLG * & $\mathrm{BLG}(\mathrm{B})^{* *}$ & $\mathrm{BLG}(\mathrm{A}) * *$ \\
\hline $\mathrm{n} \mathrm{H}^{+}(\mathrm{mol} / \mathrm{mol})$ & $-0.51 \pm 0.04$ & $-0.51 \pm 0.04$ & $-0.421 \pm 0.018$ & $-0.584 \pm 0.050$ \\
\hline$K_{\mathrm{a}}\left(\mathrm{M}^{-1}\right) \times 10^{-5}$ & $6.0 \pm 2.8$ & $7.0 \pm 1.2$ & $6.39 \pm 1.68$ & $8.38 \pm 1.47$ \\
\hline$\Delta \mathrm{H}(\mathrm{kJ} / \mathrm{mol})$ & $-11.3 \pm 1.1$ & $-13.10 \pm 1.25$ & $-11.39 \pm 0.60$ & $-2.54 \pm 1.65$ \\
\hline $\mathrm{T} \Delta \mathrm{S}(\mathrm{kJ} / \mathrm{mol})$ & $21.7 \pm 1.6$ & $20.27 \pm 1.31$ & $21.75 \pm 0.88$ & $31.27 \pm 1.71$ \\
\hline$\Delta \mathrm{G}(\mathrm{kJ} / \mathrm{mol})$ & $-33.0 \pm 1.2$ & $-33.36 \pm 0.41$ & $-33.14 \pm 0.65$ & $-33.81 \pm 0.43$ \\
\hline
\end{tabular}

*Values from (Loch et al., 2015b); **Values from (Loch et al., 2013b)

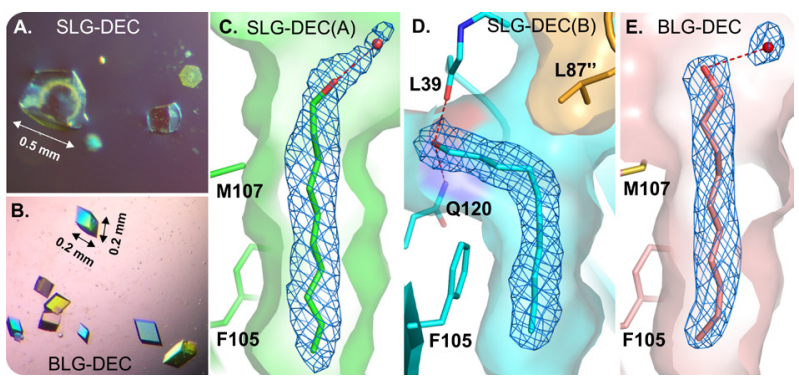

Figure 5. Crystals of (A) SLG-DEC and (B) BLG-DEC complexes. The quality of electron density maps (2FoFc, $1.00 \sigma)$ around decanol molecule in SLG-DEC dimer subunit A (C), dimer subunit B (D) and in BLG-DEC complex (E).

failed, so we screened other aliphatic ligands to find those that facilitate crystallization. Among them, only decanol gave promising results. As the structure of reference protein (BLG) complex with decanol was unknown we also crystallized BLG in the presence of DEC.

The crystals of BLG-DEC complex had symmetry of P321 space group, which is typical for most of the BLG-ligand complexes (Cherrier et al., 2013; Loch et al., 2016; Rovoli et al., 2018). The flexible loops, EF and $\mathrm{GH}$, were in open conformation which is common for bovine lactoglobulin structures determined at $\mathrm{pH}$ above 7.5 (Qin et al., 1998). The asymmetric part of the unit cell contained one protein chain. The DEC molecule was bound in the hydrophobic part of the $\beta$-barrel and possessed an extended conformation (Fig. 5E).

The crystals of sheep $\beta$-lactoglobulin complex with decanol were obtained using sodium citrate as precipitant but they appeared after much longer time (approx. 3 months) than crystals of BLG-DEC complex, which grew under similar conditions within 2-3 days. Their morphology was also different than observed for BLG crystals (Fig. 5). Hexagonal crystals of SLG-DEC complex had symmetry of space group $\mathrm{P}_{2}$ that was not observed previously for any $\beta$-lactoglobulin crystals. The

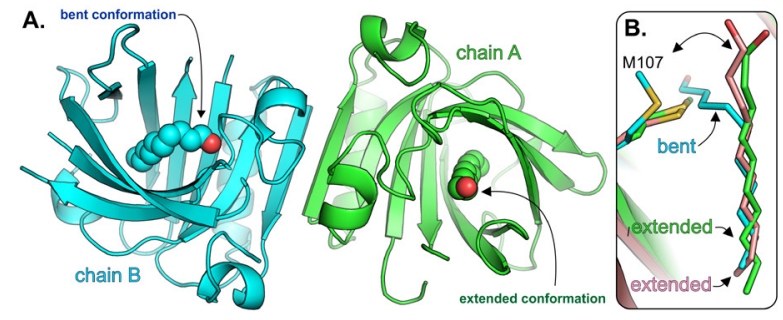

Figure 6. (A) Asymmetric dimer in the crystal structure of the SLG-DEC complex. (B) Differences in ligand conformation in SLG-DEC subunit A (green), SLG-DEC subunit B (cyan) and in BLG-DEC complex (light pink).
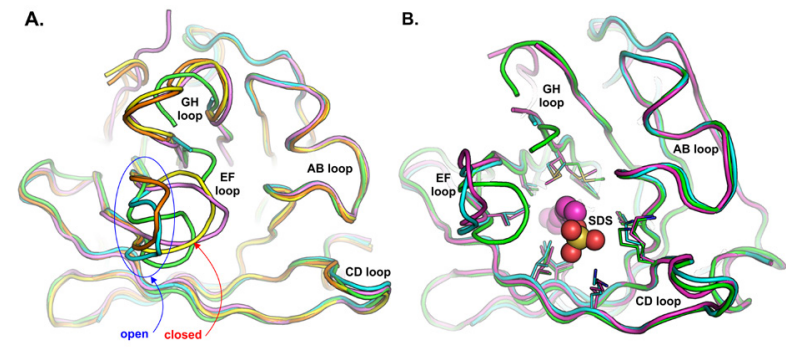

Figure 7. (A) Lactoglobulin structures with different conformations of EF and GH loops.

Superposition of the ovine lactoglobulin: SLG-DEC subunit A (green), SLG-DEC subunit B (cyan), unliganded SLG (PDB ID: 4NLI) (violet) and bovine lactoglobulin structures (PDB IDs: 3BLG and 1BSY). (B) Superposition of SLG-DEC subunit A (green), SLG-DEC subunit $B$ (cyan) and the structure of BLG-SDS complex (magenta) (PDB ID: 4IBA).

asymmetric part of the unit cell contained SLG dimer of pseudo-two-fold symmetry (Fig. 6). Electron density was well defined for the entire molecule except for disordered N-terminal residues and GH loop in both subunits. The Fourier maps revealed the presence of decanol molecule bound in the $\beta$-barrel of each subunit (Fig. 5, Fig. 6).

Both SLG-DEC subunits had a very similar but not identical structure. The differences were observed for the main chain atoms in loops EF, GH (Fig. 7A) and for the small loops $\mathrm{DE}$ and $\mathrm{BC}$ at the $\beta$-barrel bottom. The EF loop in subunit B had an open conformation typical for LG-ligand complexes while residues Ala86 and Leu87 from EF loop in subunit A were shifted by up to $6.5 \AA$ towards the position observed in the closed conformation of the loop (Fig. 7A). This "half-open" conformation is unique and different than conformations summarized and classified in our previous study (Loch et al., 2015a). The GH loop in both chains was partially disordered, which is frequently observed in bovine lactoglobulin structures with an open EF loop (Loch et al., 2012; Loch et al., 2015a).

Subunits A and B in the SLG-DEC structure differed in the conformation not only of flexible loops but also of decanol molecule bound in the $\beta$-barrel (Fig. 6). In the chain $A$, similarly as in the BLG-DEC structure (Fig. 5E and Fig. 6B), the decanol aliphatic chain had an extended conformation, which is typical for hydrocarbon chain in known bovine $\beta$-lactoglobulin complexes with fatty acids (Wu et al., 1999; Kontopidis et al., 2002; Loch et al., 2013a). Also, the position of the decanol hydroxyl group in the SLG-DEC subunit A was similar to the one observed in BLG-DEC structure and BLG complex with decanoic acid (PDB ID: 3NQ3) (Loch et al., 2011). In the SLG-DEC subunit B, the ligand was bent and its hydroxyl group made hydrogen bonds to 
NE2 atom of $\operatorname{Gln} 120(3.20 \AA)$ and to carbonyl atom of Leu39 (2.67 $\AA$ ) (Fig. 5D). The oxygen atom was located close to the position which in subunit A was occupied by Met107 (Fig. 6B). It is interesting to notice that in crystals of unliganded bovine $\beta$-lactoglobulin (e.g. PDB ID:1BSY) and in some BLG-ligand complexes (e.g. PDB ID: $3 \mathrm{NQ} 3$ and SLG-DEC subunit A) the position taken by decanol hydroxyl group was occupied by a water molecule.

\section{DISCUSSION}

\section{Ligand binding to SLG}

The bovine $\beta$-lactoglobulin, which is the most intensively studied lactoglobulin, can bind a wide range of ligands (Sawyer, 2013). Our previous studies on caprine $\beta$-lactoglobulin revealed that GLG is able to bind SDS (Loch et al., 2015b) as well as local anesthetic drugs: pramocaine and tetracaine (Loch et al., 2015a) in a similar manner as BLG (Loch et al., 2015a). High structural and sequence homology of SLG to GLG and BLG (Loch et al., 2014) prompted us to characterize also SLG binding ability in a solution using SDS as a model ligand. The determined parameters $\Delta \mathrm{G}, \Delta \mathrm{H}, \Delta \mathrm{S}$ and the number of the exchanged protons were in a good agreement with the values obtained in our earlier studies on GLG and BLG isoform B (Loch et al., 2013b; Loch et al., 2015b). Therefore, we can conclude that differences in amino acid composition do not significantly affect the SLG ability to bind in solution ligands possessing aliphatic chain. The binding site in SLG is almost identical to that present in GLG and BLG. However, unsuccessful crystallization trials of SLG and GLG complexes with SDS or fatty acids indicate that lactoglobulin from sheep or goat milk has slightly different properties than bovine protein (Loch et al., 2014; Loch et al., 2015b).

Complexes of bovine $\beta$-lactoglobulin with hydrophobic ligands, in particular with fatty acids, can be crystallized from solutions containing sodium citrate or ammonium sulfate as the precipitant (Oliveira et al., 2001; Kontopidis et al., 2004). Despite the high structural similarity between bovine and ovine protein, confirmed by CD spectra (Fig. 3) and crystal structures of unliganded forms (Loch et al., 2014), six differences in the sequence affect the electrostatic properties of SLG and thus influenced the crystallization conditions (Loch et al., 2014) and protein interactions with anion exchange resin (Fig. 2). We observed that SLG is eluted from the column (Fig. 2) at elution volume lower than BLG isoform B (and isoform A) but similar to GLG. It indicates that ovine and caprine proteins which differ in only one residue at position N130K (Fig. 1) exhibit similar biophysical properties and crystallization behavior.

For our structural studies of SLG complexes, besides SDS, we selected fatty acids of length $C_{10}$ to $C_{18}$ that proved to form complexes with BLG (Loch et al., 2011; Loch et al., 2012). However, no crystals of SLG complex with fatty acids could be obtained neither under crystallization conditions similar to used previously for BLG nor under conditions modified by change of precipitant and buffer in the $\mathrm{pH}$ range 7.5-8.9. All the amino acids different in BLG and SLG or GLG are located relatively far from the primary binding site located in the $\beta$-barrel and do not comprise residues directly involved in protein-ligand interactions. The superposition of BLG-SDS complex (PDB: 4IBA) with each subunit of SLG-DEC structure (Fig. 7B) showed no differences explaining the difficulties in the crystallization of SLG complex with SDS. Presumably, problems have their origin in the electrostatic interactions, which in the presence of negatively charged SDS or fatty acid in the binding site prevent nucleation and/or crystal growth. This hypothesis seems to be confirmed by the successful crystallization of the SLG complex with less polar molecule, 1-decanol.

Long-chain aliphatic alcohols, as 1-decanol, are not common protein ligands but they are present in living organisms as the components of wax esters (Wahlen et al., 2009). Some studies on 1-decanol interactions with proteins were performed for 5-HT3A receptors (Decker et al., 2015), L1 neural cell adhesion molecule (Dou et al., 2011), bovine serum albumin (Reynolds et al., 1968) and horse myoglobin (Eckenhoff et al., 1999). Due to the extremely low solubility of 1-decanol in aqueous solutions, the reliable measurements of thermodynamic parameters of this alcohol binding to the protein are not possible using ITC (Malham et al., 2005). Among structures deposited in PDB, decanol is present only in a complex made by another lipocalin: mouse Major Urinary Protein 2 (MUP-2) (Malham et al., 2005). MUP-2 (PDB ID: 1ZNL) has the fold almost identical to ovine $\beta$-lactoglobulin but both sequences are very distant (only $18.6 \%$ of identity).

Superposition of SLG-DEC subunit A and BLG-DEC complex (Fig. 6B) showed that in both structures decanol occupies almost identical position and its hydroxyl group binds water molecule (Fig. 5). The structures and results of ITC measurements (Table 2) indicated that binding of 10-carbon-long or longer aliphatic ligands is driven by non-specific hydrophobic interactions, the same in bovine, ovine and caprine $\beta$-lactoglobulin.

Previous experiments with ovine and caprine $\beta$-lactoglobulins showed that their crystals have different packing than crystals of bovine protein even under similar crystallization conditions (Loch et al., 2014; Loch et al., 2015b). It is probably the result of amino acid substitutions on the protein molecule surface that do not directly affect the ligand binding but influence the molecular interactions in the crystalline phase. Also, the crystal packing probably induced an unexpected bent conformation of ligand in SLG-DEC subunit B. In this subunit, the entrance to the $\beta$-barrel is partially filled by EF loop from a symmetry-related subunit B" (Fig. 5D). The side chain of Leu87" is positioned in the place where the usually polar head of ligand is located, forcing part of decanol molecule to shift into an alternative position near the residues Gln120, Leu39, Ala118, Val41, and Met24.

\section{Conformational flexibility of ovine lactoglobulin}

The structure of SLG-DEC complex is an example of an asymmetric lactoglobulin dimer in which each subunit has different conformation of flexible loops, especially $\mathrm{EF}$ and GH. Such asymmetric dimers were observed previously in BLG structure determined under low-humidity conditions (Vijayalakshmi et al., 2008) and more recently in goat $\beta$-lactoglobulin (Loch et al., 2015b). The GLG structure obtained at $\mathrm{pH} 7.5$ contained two dimers in the asymmetric part of the unit cell but the EF loop was opened only in one of the four subunits. Interestingly, in GLG crystals obtained at $\mathrm{pH}$ 8.5, the EF loop was closed. These observations indicate that Tanford transition is triggered not only by $\mathrm{pH}$ change but probably also depends on the ionic strength of the solution and the presence of ligand. 
In crystals of SLG-DEC, the entrance to the binding pocket in chain A was directed towards a large channel filled with solvent. While position and conformation of the ligand were typical for lactoglobulin complexes, the half-open conformation of the flexible loops EF and $\mathrm{GH}$ was different from expected. The analysis of molecular packing revealed that the EF loop in chain A in the open conformation would be too close to rigid CD loop from subunit B" of the neighboring molecule. Therefore, to avoid unfavorable interactions, EF and GH loops were distorted and their unusual conformation (Fig. 7A) is probably not related to the intermediate state of Tanford transition but rather to the packing of molecules.

The details of the Tanford transition were determined for the bovine $\beta$-lactoglobulin. At acidic $\mathrm{pH}$, the EF loop blocks the access to the binding pocket in the $\beta$-barrel. Such position of the loop is stabilized mostly by the hydrogen bond between Glu89 carboxyl group that possesses anomalous $\mathrm{pKa} 7.3$ (Tanford et al., 1959) and the carbonyl group of Ser116. As the $\mathrm{pH}$ increases, deprotonation of carboxyl destroys the hydrogen bond and induces a conformational change that opens access to the binding pocket. A more complex model of Tanford transition, involving also GH loop and hydrogen bonds at residues Ile84, Asn90 and Glu108, was established using NMR measurements (Sakurai \& Goto, 2006; Sakurai et al., 2009). Since glutamic acid 89 is conserved in $\beta$-lactoglobulin from almost all species, Tanford transition seems to be a common mechanism regulating access to the $\beta$-barrel which is a primary ligand binding site in $\beta$-lactoglobulins.

The nutritional value of proteins depends on their digestibility and bioavailability of the resulting peptides and amino acids. It was observed that BLG is resistant to pepsin digestion at a wide range of $\mathrm{pH}$ values (Rahaman et al., 2017) including highly acidic conditions and thus BLG can travel intact through the stomach. The BLG susceptibility for proteolysis increases in the intestine where $\mathrm{pH}$ is higher and pancreatic proteases, trypsin and chymotrypsin, are active (Rahaman et al., 2017). Lactoglobulin resistance to gastric proteases is also correlated to the occurrence of Tanford transition. In the stomach, where $\mathrm{pH}$ is low and EF loop has closed conformation that limits the access to the cleavage sites, digestibility is low. In the intestine, where $\mathrm{pH}$ rises to higher values, EF loop adopts open conformation and the protein becomes susceptible to proteases, especially to trypsin because two trypsin cleavage sites (Gasteiger et al., 2005) are present at residues 83 and 91 localized at the beginning and at the end of the EF loop. The crystal structures of SLG determined in this work in combination with the previous data (Loch et al., 2014) suggest that Tanford transition also occurs in the ovine protein, therefore it could be concluded that the mechanism of SLG digestion and its nutritional value is very similar to bovine milk lactoglobulin.

\section{CONCLUSIONS}

The results of ITC measurements together with the determined crystal structure of SLG-DEC complex (Fig. 4, Table 2) revealed that binding of aliphatic ligands by ovine lactoglobulin and its close relative, the bovine protein, is very similar. The binding constant $K_{\mathrm{a}}$ and thermodynamic parameters of SDS interactions with these three proteins are almost identical. However, despite the structural similarity to bovine $\beta$-lactoglobulin and common binding mechanism, small differences in

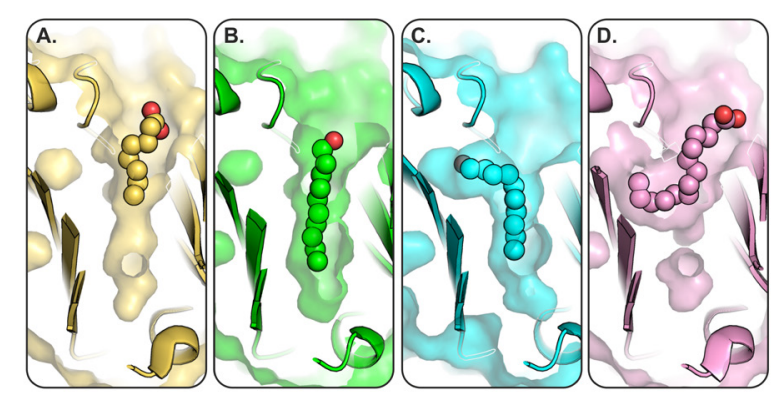

Figure 8. Different conformation of the ligand observed in lactoglobulin structures: (A) slightly curved (PDB ID: 3NQ9), (B) extended in SLG-DEC subunit $A,(C)$ bent in SLG-DEC subunit $B$ and [D] coiled conformation (PDB ID: 6RWQ).

the amino acid composition between BLG and SLG significantly influence the physicochemical properties of the ovine protein like distribution of electrostatic potentials and the pI value (Loch et al., 2014).

The conformation of ligand bound in the $\beta$-barrel is determined both by the length of the aliphatic chain and the type and flexibility of the sides chains present in the binding pocket. Four different conformations of aliphatic chain (Fig. 8) have been observed to date: (1) "extended" which is typical conformation of most aliphatic ligands having at least 10 -carbon-long aliphatic fragment located deeply in the hydrophobic part of the $\beta$-barrel (Loch et al., 2011; Loch et al., 2012); (2) "slightly curved" observed for short-chain fatty acids bound close to the $\beta$-barrel entrance (Loch et al., 2011); (3) "bent" conformation observed for the first time in SLG-DEC complex presented in this study with decanol molecule having its polar group located in the cavity between residues 39 and 120; and (4) "coiled (U-shaped)" conformation detected recently in the engineered lactoglobulin, forced by mutation F105L present in the middle part of the $\beta$-barrel (Fig. 8).

In SLG molecule, the EF loop can adopt open and closed conformation indicating that Tanford transition occurs. We demonstrated that loops in SLG possess the same conformational flexibility as observed previously for goat and bovine protein and can dynamically change their conformation under specific conditions determined by $\mathrm{pH}$, ionic strength of the solution, presence of ligand or packing of molecules in the crystalline phase. We also showed that lactoglobulin binding pocket has some degree of flexibility and can accommodate aliphatic ligands in different conformations.

\section{Acknowledgements}

The authors would like to thank Magdalena Kopeć for participation in the crystallization experiments.

\section{REFERENCES}

Bonarek P, Polit A (2018) Systematic calorimetric studies of proton exchange associated with binding of beta-lactoglobulin with ligand. Int J Biol Macromol 120: 128-134. https://doi.org/10.1016/J.IJBIOMAC.2018.08.012

Cherrier M V, Engilberge S, Amara P, Chevalley A, Salmain M, Fontecilla-Camps JC (2013) Structural basis for enantioselectivity in the transfer hydrogenation of a ketone catalyzed by an artificial metalloenzyme. Eur J Inorg Chem 2013: 3596-3600. https://doi. org/10.1002/ejic.201300592

Ciuciu A-MS, Aprodu I, Alexe P, Stănciuc N (2016) Thermally driven interactions between $\beta$-lactoglobulin and retinol acetate investigated by fluorescence spectroscopy and molecular modeling methods. 
Dairy Sci Technol 96: 405-423. https://doi.org/10.1007/s13594-015$0277-7$

Claeys WL, Verraes C, Cardoen S, De Block J, Huyghebaert A, Raes K, Dewettinck K, Herman L (2014) Consumption of raw or heated milk from different species: An evaluation of the nutritional and potential health benefits. Food Control 42: 188-201. https://doi. org/10.1016/J.FOODCONT.2014.01.045

Decker A-M, Witten S, Barann M, Urban BW (2015) Fast and slow interactions of n-alkanols with human 5-HT3A receptors: Implications for anesthetic mechanisms. Biocbim Biophys Acta 1848: 1524 1535. https://doi.org/10.1016/j.bbamem.2015.03.032

Dou X, Menkari CE, Shanmugasundararaj S, Miller KW, Charness ME (2011) Two alcohol binding residues interact across a domain interface of the L1 neural cell adhesion molecule and regulate cell adhesion. J Biol Chem 286: 16131-16139. https://doi.org/10.1074/ ibc.M110.209254

Eckenhoff RG, Tanner JW, Johansson JS (1999) Steric hindrance is not required for n-alkanol cutoff in soluble proteins. Mol Pharmacol 56: $414-418$

El-Zahar K, Sitohy M, Dalgalarrondo M, Choiset Y, Métro F, Haertlé T, Chobert J-M (2004) Purification and physicochemical characterization of ovine beta-lactoglobulin and alpha-lactalbumin. Nahrung 48: 177-183. https://doi.org/10.1002/food.200300447

Emsley P, Lohkamp B, Scott WG, Cowtan K (2010) Features and development of Coot. Acta Crystallogr D Biol Crystallogr 66: 486-501. https://doi.org/10.1107/S0907444910007493

Evans PR, Murshudov GN (2013) How good are my data and what is the resolution? Acta Crystallogr D Biol Crystallogr 69: 1204-1214. https://doi.org/10.1107/S0907444913000061

Gasteiger E, Hoogland C, Gattiker A, Duvaud S, Wilkins MR, Appel RD, Bairoch A (2005) Protein Identification and Analysis Tools on the ExPASy Server. In The Proteomics Protocols Handbook, pp 571-607. Totowa, NJ: Humana Press

Gowda V, Foulke-Abel J, Agbo H, Bench BJ, Chae J, Russell WK, Watanabe CMH (2017) Lipofuscin formation catalyzed by the milk protein $\beta$-lactoglobulin: lysine residues in cycloretinal synthesis. Biochemistry 56: 5715-5719. https://doi.org/10.1021/acs. biochem.7b00709

Hernández-Ledesma B, Recio I, Amigo L (2008) B-Lactoglobulin as source of bioactive peptides. Amino Acids 35: 257-265. https://doi. org/10.1007/s00726-007-0585-1

Kontopidis G, Holt C, Sawyer L (2002) The ligand-binding site of bovine beta-lactoglobulin: evidence for a function? I Mol Biol 318: 1043-1055. https://doi.org/10.1016/S0022-2836(02)00017-7

Kontopidis G, Holt C, Sawyer L (2004) Invited review: beta-lactoglobulin: binding properties, structure, and function. I Dairy Sci 87: 785796. https://doi.org/10.3168/jds.S0022-0302(04)73222-1

Kurpiewska K, Biela A, Loch JI, Swiątek S, Jachimska B, Lewiński K (2018) Investigation of high pressure effect on the structure and adsorption of $\beta$-lactoglobulin. Colloids Surfaces B Biointerfaces 161: $387-$ 393. https://doi.org/10.1016/j.colsurfb.2017.10.069

Leeb E, Kulozik U, Cheison S (2011) Thermal pre-treatment of $\beta$-Lactoglobulin as a tool to steer enzymatic hydrolysis and control the release of peptides. Procedia Food Sci 1: 1540-1546. https://doi. org/10.1016/J.PROFOO.2011.09.228

Loch J, Polit A, Górecki A, Bonarek P, Kurpiewska K, DziedzickaWasylewska M, Lewiński K (2011) Two modes of fatty acid binding to bovine $\beta$-lactoglobulin - crystallographic and spectroscopic studies. I Mol Recognit 24: 341-349. https://doi.org/10.1002/jmr.1084

Loch JI, Bonarek P, Polit A, Jabłoński M, Czub M, Ye X, Lewiński $\mathrm{K}$ (2015a) $\beta$-Lactoglobulin interactions with local anaesthetic drugs - Crystallographic and calorimetric studies. Int J Biol Macromol 80: 87-94, https://doi.org/10.1016/j.ijbiomac.2015.06.013

Loch JI, Bonarek P, Polit A, Riès D, Dziedzicka-Wasylewska M, Lewiński K (2013a) Binding of 18-carbon unsaturated fatty acids to bovine $\beta$-lactoglobulin - Structural and thermodynamic studies. Int I Biol Macromol 57: 226-231. https://doi.org/10.1016/j.ijbiomac.2013.03.021

Loch JI, Bonarek P, Polit A, Świątek S, Czub M, Ludwikowska M, Lewiński K (2015b) Conformational variability of goat $\beta$-lactoglobulin: crystallographic and thermodynamic studies. Int J Biol Macromol 72: 1283-1291. https://doi.org/10.1016/j.ijbiomac. 2014.10.031

Loch JI, Bonarek P, Polit A, Swiątek Ś, Dziedzicka-Wasylewska M, Lewiński K (2013b) The differences in binding 12-carbon aliphatic ligands by bovine $\beta$-lactoglobulin isoform $\mathrm{A}$ and $\mathrm{B}$ studied by isothermal titration calorimetry and X-ray crystallography. I Mol Recognit 26: 357-367. https://doi.org/10.1002/jmr.2280

Loch JI, Bonarek P, Tworzydło M, Lazińska I, Szydłowska J, Lipowska J, Rzęsikowska K, Lewiński K (2018) The engineered B-lactoglobulin with complementarity to the chlorpromazine chiral conformers. Int J Biol Macromol 114: 85-96. https://doi. org/10.1016/J.IJBIOMAC.2018.03.074

Loch JI, Bonarek P, Tworzydło M, Polit A, Hawro B, Lach A, Ludwin E, Lewiński $K$ (2016) Engineered $\beta$-lactoglobulin produced in e. coli: purification, biophysical and structural characterisation. Mol Biotechnol 58: 605-618. https://doi.org/10.1007/s12033-016-9960-z

Loch JI, Molenda M, Kopeć M, Swiątek S, Lewiński K (2014) Structure of two crystal forms of sheep $\beta$-lactoglobulin with EF-loop in closed conformation. Biopolymers 101: 886-894. https://doi. org/10.1002/bip.22471

Loch JI, Polit A, Bonarek P, Olszewska D, Kurpiewska K, DziedzickaWasylewska M, Lewiński K (2012) Structural and thermodynamic studies of binding saturated fatty acids to bovine $\beta$-lactoglobulin. Int J Biol Macromol 50: 1095-1102. https://doi.org/10.1016/j.ijbiomac.2012.03.002

Malham R, Johnstone S, Bingham RJ, Barratt E, Phillips SE V, Laughton CA, Homans SW (2005) Strong solute-solute dispersive interactions in a protein-ligand complex. I Am Chem Soc 127: 1706117067. https://doi.org/10.1021/ja055454g

Martorell-Aragonés A, Echeverría-Zudaire L, Alonso-Lebrero E, BonéCalvo J, Martín-Muñoz MF, Nevot-Falcó S, Piquer-Gibert M, Valdesoiro-Navarrete L (2015) Position document: IgE-mediated cow's milk allergy. Allergol Immunopathol (Madr) 43: 507-526. https:/ / doi.org/10.1016/J.ALLER.2015.01.003

Le Maux S, Bouhallab S, Giblin L, Brodkorb A, Croguennec T (2014) Bovine $\beta$-lactoglobulin/fatty acid complexes: binding, structural, and biological properties. Dairy Sci Technol 94: 409-426. https://doi. org/10.1007/s13594-014-0160-y

McCoy AJ, Grosse-Kunstleve RW, Adams PD, Winn MD, Storoni LC, Read RJ (2007) Phaser crystallographic software. J Appl Crystallogr 40: 658-674. https://doi.org/10.1107/S0021889807021206

Murshudov GN, Skubák P, Lebedev AA, Pannu NS, Steiner RA, Nicholls RA, Winn MD, Long F, Vagin AA (2011) REFMAC5 for the refinement of macromolecular crystal structures. Acta Crystallogr D Biol Crystallogr 67: 355-367. https://doi.org/10.1107/ S0907444911001314

Oliveira KM, Valente-Mesquita VL, Botelho MM, Sawyer L, Ferreira ST, Polikarpov I (2001) Crystal structures of bovine beta-lactoglobulin in the orthorhombic space group C222(1). Structural differences between genetic variants A and B and features of the Tanford transition. Eur J Biochem 268: 477-483

Pérez MD, Calvo M (1995) Interaction of beta-lactoglobulin with retinol and fatty acids and its role as a possible biological function for this protein: a review. J Dairy Sci 78: 978-988. https://doi. org/10.3168/jds.S0022-0302(95)76713-3

Power O, Fernández A, Norris R, Riera FA, FitzGerald RJ (2014) Selective enrichment of bioactive properties during ultrafiltration of a tryptic digest of $\beta$-lactoglobulin. J Funct Foods 9: 38-47. https://doi. org/10.1016/J.JFF.2014.04.002

Qin BY, Bewley MC, Creamer LK, Baker HM, Baker EN, Jameson GB (1998) Structural basis of the Tanford transition of bovine beta-lactoglobulin. Biochemistry 37: 14014-14023. https://doi, org/10.1021/bi981016t

Rahaman T, Vasiljevic T, Ramchandran L (2017) Digestibility and antigenicity of $\beta$-lactoglobulin as affected by heat, $\mathrm{pH}$ and applied shear. Food Chem 217: 517-523. https://doi.org/10.1016/j.foodchem.2016.08.129

Reynolds JA, Herbert S, Steinhardt J (1968) Binding of some longchain fatty acid anions and alcohols by bovine serum albumin. Biochemistry 7: 1357-1361. https://doi.org/10.1021/bi00844a016

Rovoli M, Thireou T, Choiset Y, Haertlé T, Sawyer L, Eliopoulos E, Kontopidis G (2018) Thermodynamic, crystallographic and computational studies of non-mammalian fatty acid binding to bovine B-Lactoglobulin. Int J Biol Macromol 118: 296-303. https://doi. org/10.1016/j.ijbiomac.2018.05.226

Sakurai K, Goto Y (2006) Dynamics and mechanism of the Tanford transition of bovine beta-lactoglobulin studied using heteronuclear NMR spectroscopy. J Mol Biol 356: 483-496. https://doi. org/10.1016/j.jmb.2005.11.038

Sakurai K, Konuma T, Yagi M, Goto Y (2009) Structural dynamics and folding of beta-lactoglobulin probed by heteronuclear NMR. Biochim Biophys Acta 1790: 527-537. https://doi.org/10.1016/j.bbagen.2009.04.003

Sawyer L (2013) Advanced Dairy Chemistry: Volume 1A: Proteins: Basic Aspects. Adv Dairy Chem 211-259. https://doi.org/10.1007/9781-4614-4714-6_7

Silveira ST, Martínez-Maqueda D, Recio I, Hernández-Ledesma B (2013) Dipeptidyl peptidase-IV inhibitory peptides generated by tryptic hydrolysis of a whey protein concentrate rich in $\beta$-lactoglobulin. Food Chem 141: 1072-1077. https://doi.org/10.1016/J.FOODCHEM.2013.03.056

Skerra A (2008) Alternative binding proteins: anticalins - harnessing the structural plasticity of the lipocalin ligand pocket to engineer novel binding activities. FEBS J 275: 2677-2683. https://doi. org/10.1111/j.1742-4658.2008.06439.x

Tanford C, Bunville LG, Nozaki Y (1959) The Reversible Transformation of $\beta$-Lactoglobulin at $\mathrm{pH} 7.5$ 1. J Am Chem Soc 81: 4032-4036. https://doi.org/10.1021/ja01524a054

Tsutsumi R, Tsutsumi YM (2014) Peptides and proteins in whey and their benefits for human health. Austin J Nutr Food Sci 1: 1002. 
https:/ / austinpublishinggroup.com/nutrition-food-sciences/fulltext/ ajnfs-v1-id1002.php

Tulipano G, Faggi L, Nardone A, Cocchi D, Caroli AM (2015) Characterisation of the potential of $\beta$-lactoglobulin and $\alpha$-lactalbumin as sources of bioactive peptides affecting incretin function: In silico and in vitro comparative studies. Int Dairy J 48: 66-72. https://doi. org/10.1016/j.idairyj.2015.01.008

Vijayalakshmi L, Krishna R, Sankaranarayanan R, Vijayan M (2008) An asymmetric dimer of beta-lactoglobulin in a low humidity crystal form - structural changes that accompany partial dehydration and protein action. Proteins 71: 241-249. https://doi.org/10.1002/ prot. 21695

Villa C, Costa J, Oliveira MBPP, Mafra I (2018) Bovine milk allergens: A comprehensive review. Compr Rev Food Sci Food Saf 17: 137-164. https://doi.org/10.1111/1541-4337.12318
Wahlen BD, Oswald WS, Seefeldt LC, Barney BM (2009) Purification, characterization, and potential bacterial wax production role of an NADPH-dependent fatty aldehyde reductase from Marinobacter aquaeolei VT8. Appl Environ Microbiol 75: 2758-2764. https://doi. org/10.1128/AEM.02578-08

Winn MD, Ballard CC, Cowtan KD, Dodson EJ, Emsley P, Evans PR, Keegan RM, Krissinel EB, Leslie AGW, McCoy A, McNicholas SJ, Murshudov GN, Pannu NS, Potterton EA, Powell HR, Read RJ, Vagin A, Wilson KS (2011) Overview of the CCP4 suite and current developments. Acta Crystallogr D Biol Crystallogr 67: 235-242. https://doi.org/10.1107/S0907444910045749

Wu SY, Pérez MD, Puyol P, Sawyer L (1999) beta-lactoglobulin binds palmitate within its central cavity. J Biol Chem 274: 170-174.

Zeece M, Huppertz T, Kelly A (2008) Effect of high-pressure treatment on in-vitro digestibility of $\beta$-lactoglobulin. Innov Food Sci Emerg Technol 9: 62-69. https://doi.org/10.1016/J.IFSET.2007.05.004 